\title{
Body Image Dissatisfaction, Eating Disorders, and Associated Factors in Brazilian Professional Ballroom Dancers
}

\author{
Allana Alexandre Cardoso, MSc, Nycolle Martins Reis, MSc, Jéssica Moratelli, MSc, Adriano \\ Borgatto, PhD, Rui Resende, PhD, Fernanda Christina de Souza Guidarini, PhD, and \\ Adriana Coutinho de Azevedo Guimarães, $\mathrm{PhD}$
}

\begin{abstract}
The search for movement plasticity causes dancers to seek to achieve and maintain low body weight, which can lead to dissatisfaction with their body image and to eating disorders. The purpose of this study was to analyze body image satisfaction and the presence of eating disorders and associated factors in professional ballroom dancers in Brazil. Three hundred and twenty dancers took part via a self-reported questionnaire. The majority of the dancers proved to be dissatisfied with their body image; the increase with age of body mass index (BMI) influenced the dissatisfaction due to excess weight. It is concluded that body image is associated with eating disorders, age, and BMI in ballroom dancers.
\end{abstract}

$\mathrm{D}$ edication to a professional career in dance requires a high level of functional aptitude and an aesthetically beautiful body. ${ }^{1,2}$
Thus, professional dancers search for maximum artistic and visual expression that is literally embodied in the demand for excellent physical qualities and great biomechanical and physiological capabilities. ${ }^{1,3-5}$

Due to intense concern with aesthetic standards, dancers tend to maintain thin bodies, ${ }^{6-9}$ which can lead to discomfort with body image. ${ }^{9-11}$ Studies have indicated that independent of sex and age, it is common for individuals, even those at their ideal weight, to be dissatisfied with their bodies. ${ }^{8,12,13}$ This favors the desire to lose weight, stimulating the practice of behaviors at risk for the development of eating disorders, ${ }^{14}$ as has previously been observed in numerous dance genres. ${ }^{10,15,16}$ Individuals who are dissatisfied with their body may adopt harmful behaviors (e.g.,
Allana Alexandre Cardoso, MSc, Post-Graduate Program in Physical Education, Federal University of Santa Catarina, Florianopolis, Brazil. Nycolle Martins Reis, MSc, Center of Sciences of Health and Sport, State University of Santa Catarina, Florianopolis, Brazil. Jéssica Moratelli, MSc, Post-Graduate Program in Human Movement Sciences, State University of Santa Catarina, Florianopolis, Brazil. Adriano Borgatto, PhD, Department of Informatics and Statistics and PostGraduate Program in Physical Education, Federal University of Santa Catarina, Florianópolis, Brazil. Rui Resende, PhD, University Institute of Maia, Maia, Portugal. Fernanda Christina de Souza Guidarini, PhD, State University of Santa Catarina, Florianopolis, Brazil. Adriana Coutinho de Azevedo Guimarães, $\mathrm{PhD}$, Department of Physical Education and Post-Graduate Program in Human Movement Sciences, Health and Sports Sciences Center of the State University of Santa Catarina, Florianopolis, Brazil.

Correspondence: Allana Alexandre Cardoso, MSc, Laboratorio de Pedagogia do Esporte, Centro de Desportos, Campus Reitor Joao David Ferreira Lima, s/n, Trindade Florianopolis, SC, CEP 88040900, Brazil; allana.alexandre@gmail.com. restrict food intake) or have negative emotional reactions (e.g., feelings of sadness, depressive symptoms, and anxiety disorder). This can contribute to the onset and persistence of eating disorders. ${ }^{16}$

Despite the fact that body image dissatisfaction and the presence of eating disorders represent themes of great importance among professional dancers, there is a notable lack of studies that propose to investigate these variables in the context of professional ballroom dancing. ${ }^{7}, 17$ Although there is a wealth of health-related scientific studies that involve the more widely known dance genres such as classical ballet and contemporary dance, it must be pointed out that the dedication to studying, training, and rehearsals demanded of professional ballroom dancers can be as intense as in other genres. This emphasizes the need of this population to be the focus of similar investigations, above all to alert them of the possible risks involved in body image dissatisfaction and behaviors that propel them into eating disorders. Thus, the objective of this study was to analyze body image satisfaction, the presence of eating disorders, and the associated factors of age, sex, and body mass index in professional ballroom dancers in Brazil.

\section{Material and Methods}

This cross-sectional design project was approved by the Ethics in Research involving Human Beings Commit- 
tee (CEPSH) of the State University of Santa Catarina, Brazil, process no. 1.320.412.

The inclusion criteria for participation in this study were as follows: professional dancers of either sex, who were over 18 years of age and practiced ballroom dancing for a minimum of 6 years and participated in classes, training, and rehearsals in a systematized way for a minimum of three times a week and were contracted by a professional ballroom dance company or part of the teaching body of a ballroom dance academy or school at the time of data collection. Those excluded from the study were dancers with less than 6 years of contact with ballroom dance, amateur dancers who were unpaid and did not work professionally in this field, and those who exclusively practiced dance modalities other than ballroom. Also excluded was anyone who answered the questionnaire described below inappropriately.

Registries made available online of regional associations such as the $\mathrm{Na}$ tional Ballroom Dancing Association in Brazil (ANDANÇAS), the Brazilian Ballroom Dancing Commission (CBDS), the Santa Catarina Ballroom Dancing Association (ACADS), and the Association of Professional Ballroom Dancers of Rio de Janeiro, Brazil (APDS), were surveyed and used to invite registered professionals to take part in the study.

\section{Data Collection}

Contact was made with schools and dancers by phone or digital means between November 2016 and June 2017. After accepting the invitation to participate and signing a Free and Clarified Term of Consent (FCTC), the questionnaire was sent via Google Docs. The questionnaire was self-reported and divided into three blocks: general information, body image satisfaction, and eating disorders.

\section{General Information}

The general information collected from participants included age, sex, extent of systematized practice of ballroom dancing, weekly contact with ballroom dancing in days per week, practice of other types of dance, and practice of other physical activities.

The body mass and height used to calculate the body mass index (BMI) were self-reported as a function of the online collection. The weight status of the individual was classified according to the cut-off points established by the World Health Organization: BMI below $18.5 \mathrm{~kg} / \mathrm{m}^{2}=$ underweight; those between 18.5 and $24.9 \mathrm{~kg} / \mathrm{m}^{2}$ = ideal weight (eutrophic); 25 to 29.9 $\mathrm{kg} / \mathrm{m}^{2}=$ overweight; and above 30 $\mathrm{kg} / \mathrm{m}^{2}=$ obese. ${ }^{18}$ For this study, due to the low number of underweight dancers, they were added to the ideal weight category. Similarly, due to the low number overweight and obese dancers, they were combined as the excess weight category. Thus, for the statistical analyses two categories were adopted, normal weight and excess weight.

\section{Body Image Satisfaction}

Assessment of body image satisfaction was obtained using a scale of nine body silhouettes ${ }^{19,20}$ that presented a continuum from thin (silhouette 1) to severely obese (silhouette 9), and replies to two questions: 1 . which silhouette best represents your current physical appearance (true image) and 2. which silhouette would you like to have (ideal image)? To verify the degree of satisfaction with his or her image, the score for the true image chosen was subtracted from the score for the ideal image chosen. When the difference between the two was zero, the individual was classified as satisfied, and when different from zero as dissatisfied. If the result was negative, the dissatisfaction was due to thinness, and when positive due to overweight.

\section{Eating Disorders}

These were evaluated using the Eating Attitudes Test (EAT-26), ${ }^{21,22}$ which provides indications for a prognosis of anorexia nervosa. This instrument is composed of 26 questions subdivided into three scales: diet; bulimia and concerns with food; and the oral control. The final score can vary from 0 to 78 points, and the final classifi- cation is divided into two categories: presence of symptoms (EAT-26 $\geq 21$ ) and absence of symptoms (EAT-26< 21). ${ }^{22,23}$ The Bulimic Inventory Test Edinburgh (BITE) ${ }^{24-26}$ is a questionnaire composed of 33 questions divided into two scales that track and evaluate the gravity of bulimia nervosa. Specifically, the symptom scale allows for classification of the degree of bulimic symptoms present, with a maximum of 30 points; the gravity scale provides an index based on the frequency of compulsive and purgative behaviors, with a maximum of 10 points. ${ }^{24}$ For statistical analyses of the data from both instruments, EAT-26 and BITE, the authors opted to use the values generated by the final scores in order to facilitate understanding of the results.

\section{Data Analysis}

Data analysis was carried out using IBM SPSS Statistics software version 20 (IBM, Armonk, New York, USA). Descriptive statistics were used, including mean values, standard deviation, absolute and relative frequency, and confidence intervals. Multinomial logistic regression (MLR) was used to estimate the rates of unadjusted and adjusted chances and the likelihood-ratio test was used for normal distribution. Multinomial logistic regression is the regression analysis to be used when the dependent variable is nominal with more than two levels. It is a predictive analysis test that explains the relationship between one nominal dependent variable and one or more independent variables. In this case, variables presenting $\mathrm{p}<$ 0.20 in at least one of the body image categories in the crude analysis were included in the selection model, and the category "satisfied with body image" was adopted as the reference for the analysis. The level of significance throughout was $\mathrm{p}<0.05$.

\section{Results}

The intentional probabilistic sample for this study was composed of 320 professional ballroom dancers, 187 of whom were men. The mean age for both sexes was $31.48 \pm 8.63$ years. 
They had between 6 and 10 years of professional experience in ballroom dancing and practiced ballroom dancing from 5 to 7 times per week. Some performed forms of dance other than ballroom (48.8\%) and other physical activities besides dance (72.8\%), of which resistance exercise (running, cycling, functional training, among others) was mentioned most often. As for BMI, the general average of the participants was 24.42 $\pm 4.02 \mathrm{~kg} / \mathrm{m}^{2}$, indicating that they were in the weight range considered normal for adults. However, when analyzed by sex, better scores were observed for women $(22.84 \pm 4.26)$, who had normal weight, while the men $(25.49 \pm 3.48)$ were overweight. In the evaluation of body image satisfaction (Fig. 1), it can be seen that the majority of the dancers were dissatisfied due to excess weight, especially the women $(56.4 \%)$ when compared to the men $(55.6 \%)$. Similar data are presented by Fonseca and Gama, ${ }^{27}$ who, when investigating ballroom dance practitioners of both sexes, concluded that women were more dissatisfied with their body image than men. Numerous studies affirm the concept that in general body dissatisfaction is linked to dance, a discipline in which leanness is desireable. , $28,29^{2}$

Mean scores for the instruments used to measure the symptomology of eating disorders show that the majority of the dancers scored low on both the EAT $(11.18 \pm 9.31)$ and BITE $(7.01 \pm 4.82)$ symptom scales, indicating a low risk of developing eating disorders. However, although the means were not high, $74.1 \%$ of the dancers scored higher on the BITE gravity scale $(6.74 \pm 2.86)$, the scale that provides an index based on the frequency of compulsive and purgative behaviors, providing evidence of the occurrence of this type of disorder among the dancers evaluated.

With respect to the factors associated with body image satisfaction (Table 1), it can be seen that the dancers had a 3\% increased chance of dissatisfaction due to excess weight with increase in age $(\mathrm{p}=0.099)$, and $51 \%$ more from increase in BMI $(\mathrm{p}$ $\leq 0.001)$. In addition, there was a tendency for dancers with higher EAT scores to present a $3 \%$ greater chance of dissatisfaction due to being overweight $(\mathrm{p}=0.116)$, and those with higher BITE scores on the symptoms scale to have a $28 \%$ greater chance of the same dissatisfaction $(\mathrm{p} \leq 0.001)$.

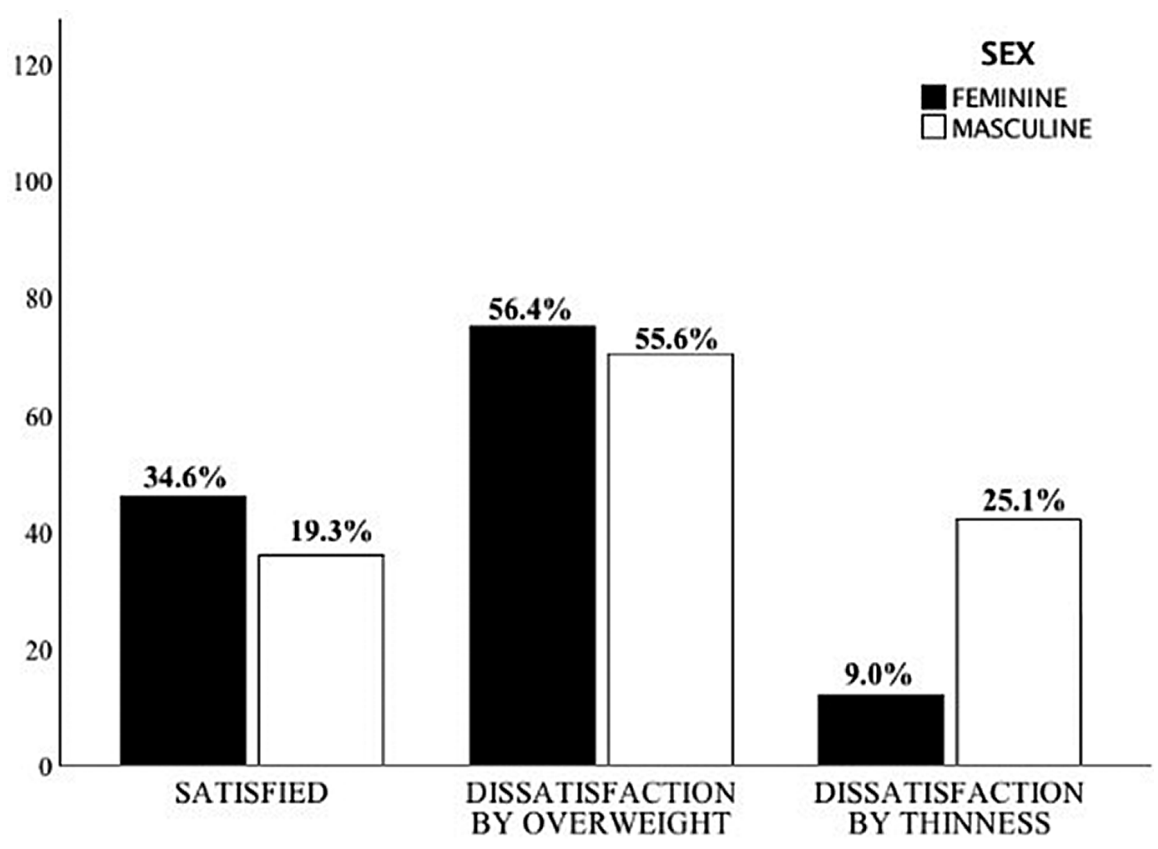

Figure 1 Body image satisfaction in professional Brazilian ballroom dancers by sex, 2016 to 2017.
As to dissatisfaction due to being underweight, it can be seen from Table 1 that there was a 96\% lesser chance for women dancers to be dissatisfied due to being underweight compared to men $(\mathrm{p} \leq 0.001)$. On the other hand, dancers with a lower BMI showed a $35 \%$ lesser chance of being dissatisfied due to being underweight $(\mathrm{p} \leq 0.001)$.

\section{Discussion}

The objective of this study was to analyze body image satisfaction in relation to the presence of eating disorders and associated factors in professional ballroom dancers in Brazil. It was shown that the majority of the dancers, female and male, were dissatisfied with their body image due to being overweight, with age and BMI being the variables that most influenced their dissatisfaction. Elevated scores on the EAT scale and BITE symptoms scale, which were frequent in the sample investigated, are negatively associated with image satisfaction due to being overweight. In addition, women were less likely to be dissatisfied with their thinness than were men.

With respect to body image dissatisfaction, other studies corroborate the results of the present study. In genres such as classical ballet, ${ }^{9,28}$ contemporary dance, ${ }^{9}$ and jazz dance, ${ }^{28}$ it has been shown that $50 \%{ }^{26}$ to $72 \%{ }^{8}$ of dancers are dissatisfied due to being overweight. In addition, high distortion levels of the body image were identified independent of the genre. ${ }^{28}$ These findings agree with those of an international study carried out with 77 semi-professional dancers of flamenco, contemporary, and neoclassical dancing, which found that $42.25 \%$ of the dancers studied had an incorrect perception of their own weight. ${ }^{6}$ It could be said that this dissatisfaction with their body image, and also the erroneous perception that many dancers have of their bodies, is a consequence of the demand to maintain an aesthetic standard and their constant need to combine physical preparation and strength with lightness and expression in their dancing. ${ }^{28}$ 
Table 1 Body Image Satisfaction in Relation to Eating Disorders and Associated Factors in Professional Ballroom Dancers in Brazil 2016 to $2017(\mathrm{~N}=320)$

\begin{tabular}{|c|c|c|c|c|}
\hline \multirow[b]{3}{*}{ Variables } & \multicolumn{4}{|c|}{ Body Image Satisfaction* } \\
\hline & \multicolumn{2}{|c|}{ Unadjusted } & \multicolumn{2}{|l|}{ Adjusted } \\
\hline & OR (CI 95\%) & P-value $\dagger$ & OR (CI 95\%) & P-value $\dagger$ \\
\hline \multicolumn{5}{|c|}{ Dissatisfied Due to Excess Weight } \\
\hline Masculine & - & - & - & - \\
\hline Feminine & $0.564(0.333 ; 0.957)$ & 0.034 & $1.684(0.691 ; 4.102)$ & 0.251 \\
\hline Age & $1.047(1.018 ; 1.077)$ & $<0.001$ & $1.038(0.993 ; 1.084)$ & 0.099 \\
\hline BMI & $1.457(1.320 ; 1.608)$ & $<0.001$ & $1.518(1.281 ; 1.799)$ & $<0.001$ \\
\hline EAT & $1.085(1.043 ; 1.128)$ & $<0.001$ & $1.039(0.991 ; 1.091)$ & 0.116 \\
\hline BITE Symptoms & $1.279(1.177 ; 1.390)$ & $<0.001$ & $1.283(1.149 ; 1.432)$ & $<0.001$ \\
\hline BITE Gravity & $1.154(1.027 ; 1.297)$ & 0.016 & $0.906(0.772 ; 1.064)$ & 0.227 \\
\hline \multicolumn{5}{|c|}{ Dissatisfied Due to Thinness } \\
\hline Masculine & - & - & - & - \\
\hline Feminine & $0.200(0.093 ; 0.431)$ & $<0.001$ & $0.042(0.013 ; 0.137)$ & $<0.001$ \\
\hline Age & $0.934(0.895 ; 0.974)$ & $<0.001$ & $0.968(0.914 ; 1.027)$ & 0.281 \\
\hline BMI & $0.770(0.691 ; 0.858)$ & $<0.001$ & $0.659(0.520 ; 0.834)$ & $<0.001$ \\
\hline EAT & $1.023(0.974 ; 1.075)$ & 0.362 & $1.039(0.978 ; 1.105)$ & 0.217 \\
\hline BITE Symptoms & $1.100(0.998 ; 1.213)$ & 0.055 & $1.095(0.960 ; 1.248)$ & 0.175 \\
\hline BITE Gravity & $1.102(0.957 ; 1.269)$ & 0.179 & $1.121(0.938 ; 1.338)$ & 0.208 \\
\hline
\end{tabular}

*The category "satisfied with body image" was adopted as the reference in the multinomial logistic regression analysis. †Likelihood ratio test. Abbreviations: EAT: Eating Attitudes Test; BITE Symptoms: symptomatic scale of the Bulimic Inventory Test Edinburgh; BITE Gravity: gravity scale of the Bulimic Inventory Test Edinburgh; OR: odds ratio; CI: confidence interval. Data fitted according to all the variables presented in the unadjusted analysis.

An analysis of risk factors for bulimia nervosa in our dancers, based on the gravity scale of the BITE instrument, showed an elevated index in the final score, indicating a tendency for compulsive and purgative behaviors. Ribeiro and Veiga ${ }^{14}$ found elevated indices for professional classical ballet dancers that identified a similar percentage of anorexia nervosa to that found in the present study (11.5\%). Similar results but with slightly higher values $(16.4 \%)$ were found for semiprofessional dancers in Spain using the EAT-26 questionnaire, ${ }^{6}$ and other Brazilian and international studies carried out using the same instruments indicated a high risk of eating disorders in professional and amateur dancers of different dance genres (ballet, jazz, and street dance). $., 29,30-32$

With respect to the sociodemographic characteristics of the professional ballroom dancers, correlations were found between dissatisfaction due to being overweight and age and BMI such that the greater the age and the BMI the greater the chances of presenting this outcome, respectively 3\% (age) and 51\% (BMI). These results suggest that, since being overweight is generally stigmatized in dance, it is probable that even with a BMI within normal limits according to WHO (2016), ${ }^{18}$ the evaluated dancers in our study considered themselves close to the limit for being classified as overweight and were consequently concerned about the need to lose weight.

Conscious of this, Santos and Amorim $^{1}$ reported that there seemed to be a consensus regarding the need for body thinness and linearity among dancers. However, the search for excessive thinness can lead to pathological situations such as the development of eating disorders. ${ }^{1,16,32}$ Hence the present study found an association between dissatisfaction with the percep- tion of being overweight and eating disorders, with a $3 \%$ greater chance for those professional dancers showing higher EAT scores and a 28\% greater chance for those presenting higher scores on the BITE symptom scale to develop these disorders. The current literature confirms these tendencies, indicating that dancers as a population are exceptionally prone to dissatisfaction due to the perception of being overweight $^{17,30,31,33}$ and consequently to eating disorder symptoms, ${ }^{3,10,16,32,34}$ all of which are $28 \%$ more prevalant in females than males. $3,8,35$

It was observed that females in our study had a $96 \%$ smaller chance of showing dissatisfaction with underweight when compared to males. This finding is in agreement with another study carried out with dancers of classical ballet, contemporary dance, and urban dance. ${ }^{9}$ We hypothesized that this is due to the fact that ballroom dancing allows for greater silhouetting 
of male dancers than female dancers; hence the emphasis on strong, virile bodies. This hypothesis is equally raised by Simas et al. ${ }^{15}$ in their study of professional ballet and contemporary dancers.

Thus, considering that physical form is one of the greatest artistic requirements on the stage and in the ballroom, demanding slim, highly functional bodies ${ }^{1}$ that are the work instrument of professional dancers, the authors suggest the need for new studies relating the variables presented in the current study to other physical characteristics present in ballroom dancing. This is in agreement with the study of Liu et al., ${ }^{17}$ who recommended the creation of intervention and prevention programs related to the health of those who dedicate themselves professionally to dancing and the search for strategies that promote a positive body image for dancers.

A limitation of this study was the use of online data collection, which made it impossible to use direct measurement instruments. On the other hand, this method of data collection provided access to the greatest possible number of professional dancers. The investigation at a national level of a population and a theme (ballroom dance) seldom addressed in the national and international literature stands out as one of the positive aspects of this study.

\section{Conclusion}

The results of this study demonstrate that the majority of our dancers were dissatisfied with their body image, due in large part to being overweight occasioned by increases in BMI as a result of aging. Higher scores on the EAT questionnaire and the BITE symptom scale were also associated with dissatisfaction due to being overweight in professional ballroom dancers.

It was found that female dancers were less likely to be dissatisfied with being underweight than male dancers. Dissatisfaction with being underweight was also reduced in dancers with lower BMI.

The results obtained in this study are intended to promote the awareness of dancers, choreographers, directors, and others involved in dance companies and schools of the importance of maintaining healthy habits to minimize the effect of factors harmful to the well-being of these professionals. The findings thus provide vital new knowledge that can be used by researchers and practitioners in designing educational materials.

Considering the importance of preventing the serious consequences caused by dissatisfaction with body image and by eating disorder symptoms, we argue for the intensification of systematic studies with professional ballroom dancers.

\section{References}

1. Santos JA, Amorim T. Desafios nutricionais de bailarinos profissionais, Rev Port Ciênc Desp. 2014;14(1):112-6.

2. de Oliveira DV, De Mello KA, Barbosa CP. Prevalência de transtornos alimentares em adolescentes praticantes de ballet clássico. Conexôes. 2013 Mar;11(1):171-87.

3. Diogo MAK, Ribas GGO, Skare TL. Frequency of pain and eating disorders among professional and amateur dancers. Sao Paulo Med J. 2016;134(6):501-7.

4. García-Dantas A, Caracuel JC. Factores que influyen en el abandono del alumnado de un conservatorio profesional de danza. Rev Iber Psicol del Ejerc Deporte. 2011;6(1):79-96.

5. Leite GSF, de Mello MT, Dáttilo M, Antunes HK. Influência do estresse em eventos competitivos relacionados à dança. EFDeportes Revista Digital. 2011 Feb;15:153.

6. Jáuregui-Lobera I, Bolaños-Ríos P, Valero-Blanco E, Ortega-de-la-Torre A. Eating attitudes, body image and risk for eating disorders in a group of Spanish dancers. Nutr Hosp. 2016 Sep;33(5):1213-21.

7. Peric M, Zenic N, Sekulic D, et al. Disordered eating, amenorrhea, and substance use and misuse among professional ballet dancers: preliminary analysis. Med Pr. 2016;67(1):21-7.

8. Robbeson JG, Kruger HS, Wright $\mathrm{HH}$. Disordered eating behavior, body image, and energy status of female student dancers. Int J Sport Nutr Exerc Metab. 2015 Aug;25(4):344-52.
9. Reis NM, Machado Z, Pelegrini A, et al. Imagem corporal, estado nutricional e sintomas de transtornos alimentares em bailarinos. Rev Bras Ativ Fís Saúde. 2013 Nov; 18(6):76381.

10. Nascimento AL, Luna JV, Fontenelle LF. Body dysmorphic disorder and eating disorders in elite professional female ballet dancers. Ann Clin Psychiatry. 2012 Aug;24(3):191-4.

11. de Moura UIS, Mendes LR, de Oliveira Silva IP, et al. Consumo alimentar, perfil antropométrico e imagem corporal de bailarinas clássicas do Vale do São Francisco. Rev Bras Nutr Esportiva. 2015;9(51):237-46.

12. Kakeshita IS, Almeida SS. Relação entre o índice de massa corporal e a percepção da auto-imagem em universitários. Rev Saúde Púb. 2006 Jun;40(3):497-504.

13. Damasceno VO, Lima JRP, Vianna JM, et al. Tipo físico ideal e satisfação com a imagem corporal de praticantes de caminhada. Rev Bras Med Esporte. 2005 May/Jun;11(3):181-6.

14. Ribeiro LG, Veiga GVd. Imagem corporal e comportamentos de risco para transtornos alimentares em bailarinos profissionais. Rev Bras Med Esporte. 2010 Mar/Apr;16(2):99-102.

15. Simas JPN, Macara A, Melo SIL. Imagem corporal e sua relação com peso e índice de massa corporal em bailarinos profissionais. Rev Bras Med Esporte. 2014 Nov/ Dec;20(6):433-37.

16. Kantanista A, Glapa A, Banio A, et al. Body image of highly trained female athletes engaged in different types of sport. Biomed Res Int. 2018 Jan 31;2018:6855751.

17. Liu J, Peh CX, Mahendran R. Body image and emotional distress in newly diagnosed cancer patients: the mediating role of dysfunctional attitudes and rumination. Body Image. 2016 Mar;20:58-64.

18. WHO, World Health Organization. The International Classification of adult underweight, overweight and obesity according to BMI, 2016. Available at: http://apps.who.int/ bmi/index.jsp?introPage=intro_3. html. Accessed June 1, 2016.

19. Stunkard J, Sorenson T, Schlusinger F. Use of the Danish Adoption Register for the study of obesity and thinness. In: Kety SS, Rowland LP, Sidman RL, Mathysse SW (eds): The Genetics of Neurological and Psy- 
chiatric Disorders. New York: Raven, 1983, pp. 115-120.

20. Scagliusu FB, Alvarenga M, Polacow $\mathrm{VO}$, et al. Concurrent and discriminant validity of the Stunkard's figure rating scale adapted into Portuguese. Appetite. 2006 Jul;47(1):77-82.

21. Garner DM, Olmsted MP, Bohr Y, Garfinkel PE. The eating attitude test: psychometric features and clinical correlates. Psychol Med. 1982 Nov;12(4):871-8.

22. Bighetti F, Santos CB, Santos JE, Ribeiro RPP. Tradução e validação do Eating Attitudes Test em adolescentes do sexo feminino de Ribeirão Preto, São Paulo. J Bras Psiquiatr. 2004 Nov/Dec;53(6):339-46.

23. Freitas S, Gorenstein C, Appolinario JC. Instrumentos para a avaliação dos transtornos alimentares. Rev Bras Psiquiatr. 2002 Dec;24(Suppl 3):34-8.

24. Henderson M, Freeman CPL. A selfrating scale for bulimia: the BITE. $\mathrm{Br}$ J Psychiatry. 1987 Jan;150(1):18-24.

25. Cordás TA, Hochgraf PO. O "BITE": instrumento para avalia- ção da bulimia nervosa-versão para o português. J Bras Psiquiatr. 1993;42:141-4.

26. Tseng MCM, Fang D, Lee MB. Comparative validity of the Chinese versions of the Bulimic Inventory Test Edinburgh and Eating Attitudes Test for DSM-IV eating disorders among high school dance and nondance students in Taiwan. Int J Eat Disord. 2014 Jan;47(1):105-11.

27. Fonseca CC, Gama EF. A imagem corporal na dança de saláo. Revista Brasileira de Ciência e Movimento. 2012;19(3):37-43.

28. Hass A, Garcia ACD, Bertoletti J. Imagem corporal e bailarinas profissionais. Rev Bras Med Esporte. 2010 May/Jun;16(3):182-5.

29. Guimarães AD, Machado SP, França AKTC, Calado IL. Transtornos alimentares e insatisfação com a imagem corporal em bailarinos. Rev Bras Med Esporte. 2014 Jul/ Aug;20(4):267-71.

30. Cardoso AA, Reis NM, Marinho AP, et al. Study of body image in professional dancers: a systematic review.
Rev Bras Med Esporte. 2017 Jul/ Aug;23(4):335-40.

31. Hincapié CA, Cassidy JD. Disordered eating, menstrual disturbances, and low bone mineral density in dancers: a systematic review. Arch Phys Med Rehabil. 2010 Nov;91(11):1777-89.

32. Arcelus J, Witcomb GL, Mitchell A. Prevalence of eating disorders amongst dancers: a systemic review and meta-analysis. Eur Eat Disord Rev. 2014 Mar;22(2):92-101.

33. Wyon MA, Allen N, Angioi M, et al. Anthropometric factors affecting vertical jump height in ballet dancers. J Dance Med Sci. 2006 Sep/ Dec;10(3\&4):106-10.

34. Padham M, Aujla I. The Relationship between passion and the psychological well-being of professional dancers. J Dance Med Sci. 2014 Mar;18(1):37-44.

35. Burckhardt P, Wynn E, Kreig MA, et al. The Effects of nutrition, puberty and dancing on bone density in adolescent ballet dancers. J Dance Med Sci. 2011 Jun;15(2):51-60. 